Article

\title{
The Dynamics of Online Activities and Its Impact on Well-Being in Urban China
}

\author{
Yinxuan Huang \\ Manchester Urban Institute, The University of Manchester, Manchester M13 9PL, UK; \\ yinxuan.huang@manchester.ac.uk
}

Received: 24 May 2018; Accepted: 19 June 2018; Published: 25 June 2018

\begin{abstract}
Using data from the China Family Panel Studies, this study examines the socioeconomic characteristics of Internet users, as well as the relationships between the dynamics of different forms of online activities and the subjective well-being of urbanites and rural migrants in urban China. The study finds that online behavior may clearly reflect differences in individuals' personal traits and socioeconomic positions. Patterns of the association between online activities and subjective well-being tend to differ among rural migrants and urbanites, especially in terms of depression. A difference-in-differences model is employed to estimate the impact of intensified engagement in online activities on depression and life satisfaction from 2010 to 2016. The results show that individuals who exhibited increased frequency of online entertainment appeared to be less depressed and more satisfied with their lives. Spending more time on online social networking has a similar impact on rural migrants, but not on urbanites. These findings suggest that the rapid development of urban China's online community has important implications for residents' subjective well-being.
\end{abstract}

Keywords: China; Internet; well-being; hukou; migrant

\section{Introduction}

China's current, unprecedented economic development is being powered by a huge influx of rural migrant workers. In the last few decades, nearly 300 million rural residents in China have left their land to work in cities across the country. Despite rural migrants' remarkable contribution to the Chinese economic miracle, their livelihood and reception in urban China have never been easy. China's unique household registration (i.e., hukou) system has created an inherent rural-urban division in Chinese cities, functioning as 'a barrier between heaven and earth' (Treiman 2012). Scholars contend that rural migrants and established urbanites tend to live parallel lives mirrored in inequalities and discriminations against rural migrants from a wide range of perspectives ( $\mathrm{Li}$ et al. 2015). Consequently, there is a growing body of literature investigating the impact of China's rapid urbanization on Chinese people's subjective well-being (Davey and Rato 2012; Easterlin et al. 2012; Jiang et al. 2012; Cheng et al. 2013; Bian and Xiao 2014). These studies have focused on a number of socioeconomic and demographic characteristics of subjective well-being. Existing findings suggest that rural migrants' urban experiences often appear to have a negative effect on their subjective well-being and mental health, as rural migrants are more likely than other urban residents to experience stress arising from social exclusion and lack of social support (Wong et al. 2007).

Owing to the development of information and communication technology (ICT) in the past decade, Internet users have become another fast-growing population in urban China. By the end of 2015, 50.3\% of the Chinese population had become Internet users, as compared to $8.5 \%$ in 2005 (World Bank 2017). Meanwhile, there are clear urban-rural disparities in terms of Internet access, with more than $70.0 \%$ of Internet users being urban residents. The ever-vibrant online society allows more research to explore how the Internet shapes personal and social life in urban China. Therefore, 
China offers an interesting case that would advance the existing scholarly understanding of the association between Internet adoption and subjective well-being (Caplan 2002; DiMaggio et al. 2004; Oh et al. 2014; Lissitsa and Chachashvili-Bolotin 2016). Notwithstanding mixed findings, the previous literature has pointed explicitly towards the observation that, in both developed and developing societies, Internet usage may have important social and psychological consequences. This gives rise to the question of how different forms of online activities affect individuals' subjective well-being in urban China, which presents a distinctive social structure underpinned by China's internal migration and its unique hukou system.

However, while subjective well-being in urban China is an urgent research topic, its relationship with the dynamics of Internet adoption remains underresearched. Against this background, the present study constructs an innovative analytical framework within which to discuss the nature and mechanisms of Internet influence on subjective well-being among urban Chinese residents. It aims to contribute to the existing research in three ways. Using data from the China Family Panel Studies, the study first examines the determinants of three types of online activities, including information acquisition, entertainment, and social networking, in urban China. Secondly, it compares differences between rural migrants and urbanites in Chinese cities in terms of the net effects of their online activities on their subjective well-being. Finally, to address design deficiencies in previous studies that have used cross-sectional data, the difference-in-differences approach is used to estimate how the dynamics of online activities may affect individuals' subjective well-being over time.

This paper is structured as follows. In the next section, we give a brief review of literature on the connection between subjective well-being and Internet penetration, paying particular attention to the context of urban China in the research paradigm. The third section gives an account of the data and methods to be used for the research, followed by the presentation of the analytical results. In its last two sections, the paper offers a discussion of the implications and conclusions, including a reflection on the limitations of the study.

\section{Theoretical Background}

\subsection{The Issue of Well-Being}

Understanding people's perceptions of their own well-being has thus far been a challenge for both academics and policy makers. The assessing of well-being consists of an objective and a subjective dimension (Cummins 1995). As far as subjective well-being is concerned, scholars have argued that it should be measured to reflect a comprehensive perception of people's lives from various aspects (Stiglitz et al. 2009). Social scientists and psychologists often use self-assessment tools to measure subjective well-being domains, including cognitive evaluations of one's life, happiness, life satisfaction, positive emotions such as joy and pride, and negative emotions such as pain and worry (Stiglitz et al. 2009; Blore et al. 2011; Hicks 2011). Previous studies on China and in other cultural contexts have either used multiple indicators to assess subjective well-being or focused on one particular domain; e.g., (Easterlin et al. 2012; Davey and Rato 2012). In this paper, subjective well-being is identified as a multi-faceted construct that includes both cognitive and affective evaluations of life.

In regard to the determinants of subjective well-being, scholars appear to agree on several points. First, a number of personal traits appear to have close connections with subjective well-being. Some researchers have reported a U-shaped association between age and subjective well-being: young and older people appear to display higher levels of subjective well-being than middle-aged people (Diener 2000; Blanchflower and Oswald 2008). In addition to age, gender and marital status have been shown to have significant effects on subjective well-being (Easterlin 2003; Bonini 2008; Lissitsa and Chachashvili-Bolotin 2016). According to studies on this topic, women and married individuals tend to enjoy higher levels of life satisfaction than men and those who are single or widowed. Secondly, the association between socioeconomic factors and subjective well-being is not self-evident, as evidenced by the ambiguous findings in this terrain. A prominent example is the debate regarding 
the Easterlin Paradox in happiness economics. The work of Richard Easterlin and later research reveal that income's effect on well-being tends to vary across different contextual backgrounds, as it is a much more positive and potent factor in developing regions than developed regions (Easterlin 1974; Diener and Diener 1995). Similarly, education has been reported as a positive correlate of well-being (Yip et al. 2007; Hicks 2011), as well as a negative correlate (Rao et al. 2014; Lissitsa and Chachashvili-Bolotin 2016). Thirdly, many studies have linked social capital to a variety of outcomes of measures of well-being. The previous literature links most of the key ingredients of social capital, including trust, social participation, social support, and neighborhood attachment, with higher levels of well-being at both individual and community levels (Helliwell 2006; Lim and Putnam 2010; Greenberg et al. 2016). The last factor to note is health, which is one of, if not the, single most consistent correlate of subjective well-being. Better health is shown to be associated with greater subjective well-being (Dolan et al. 2008). By contrast, people experiencing illnesses or other health issues are significantly more likely to feel unhappy than are their healthy counterparts (Anderson 2014).

\subsection{The Social Implications of Internet Adoption}

It is almost a cliché that the Internet plays an increasingly significant role in human society. While a vibrant and globalized market of online shopping and social media has emerged, the growing computing and mobile phone industry has also allowed users easier and more frequent access to various online activities. Researchers have therefore devoted greater effort to exploring the social outcomes prompted by the explosive development of the Internet and ICTs, such as well-being and integration (McKenna and Bargh 2000; Lissitsa and Chachashvili-Bolotin 2016).

Nevertheless, patterns of the relationship between online activities and subjective well-being appear to be ambiguous as an empirical matter. On the one hand, some findings indicate that Internet adoption is associated with increased subjective well-being (McKenna and Bargh 2000; DiMaggio et al. 2004; Elgar et al. 2011). A number of studies have revealed a positive association between online activities and perceived quality of life in Asian countries (Lee et al. 2008; Oh et al. 2014; Lissitsa and Chachashvili-Bolotin 2016). Moreover, scholars have attempted to explain the mechanisms through which Internet use may improve subjective well-being. One observation echoed among existing studies is that the Internet can meet various forms of users' human needs by promoting psychological empowerment, belongingness, learning experiences, and the like (Fowler et al. 2015). Similarly, the emergence of online communities has become a sort of social boundary that tends to separate the online 'us' and the offline 'them'. Online communities of both existing acquaintances and strangers tend to cultivate shared values and norms of reciprocal support, which can improve individuals' subjective well-being and are highly exclusive of non-Internet users (McKenna and Bargh 2000; Stepanikova and He 2010).

On the other hand, there also exists evidence of a negative relationship between Internet adoption and subjective well-being. In particular, researchers have found that Internet use might have a negative impact on social capital and mental health, both of which are considered as pivotal determinants of subjective well-being. In his landmark studies of social capital in America, Putnam (2000) argues that the decline of social connectedness in America results largely from the fact that traditional modes of social involvement have been impeded by the rise of TV, the Internet, and social media. Other researchers have expressed similar concerns, positing that online activities, not least in the form of social networking, tend to work against social connections and social participation in real-life situations and lead to decreased well-being (Valkenburg and Peter 2007). Furthermore, excessive Internet use and cyber addiction appear to have a detrimental effect on psychological well-being. Many believe that individuals who spend large amounts of time on the Internet display a higher propensity to suffer from mental problems (O'Keeffe and Clarke-Pearson 2011; Cheng and Li 2014).

The diversity of available online activities also bears a word of explanation. The ever-widening range of choices of what one can do on the Internet raises the question of whether different forms of online activities may lead to distinct social and psychological consequences. One specific 
dimension is online entertainment, which has been linked to better outcomes in individuals' quality of life. For example, internet-based leisure activities such as game-playing appear to enhance social competence and strengthen self-determinants (Ryan et al. 2006; Visser et al. 2013). As mentioned earlier, another important dimension of online engagement that has been studied widely is social networking, which is shown to have significant but rather mixed impact on depression and life satisfaction ( $\mathrm{O}^{\prime} \mathrm{Keeffe}$ and Clarke-Pearson 2011; Lissitsa and Chachashvili-Bolotin 2016). In addition, other activities such as online shopping and information gathering have also gained much attention in the previous literature (Curran et al. 2013). Therefore, it is necessary to address the diversity issue when measuring Internet adoption, as patterns of the association between Internet adoption and subjective well-being may be distinct across various online activities.

\subsection{Internet and Subjective Well-Being in the Times of Chinese Urbanization}

With regard to the determinants of subjective well-being in China, scholars have shown that a number of personal traits and socioeconomic variables, such as age, gender, income, health, social capital, and economic development, are important correlates of cognitive and affective well-being (Easterlin et al. 2012; Bian and Xiao 2014). The issue of the well-being of rural migrants in China's rapid urbanization process has gained more attention in the last decade, although findings to date have been somewhat inconclusive (Knight and Gunatilaka 2010; Nielsen et al. 2010; Nielsen et al. 2010; Jiang et al. 2012; Cheng et al. 2013). As migration experiences are often subject to such problems as unequal policy treatment, long working hours, and public health issues, some argue that rural migrants tend to report lower levels of subjective well-being compared to urban migrants and urban locals (Knight and Gunatilaka 2010; Easterlin et al. 2012). Hukou-related inequalities and disadvantages in particular tend to erode the happiness of migrants (Jiang et al. 2012). By contrast, Nielsen and his colleagues' research in Beijing and in the province of Fujian suggests that the circular nature of rural migration, whereby peasant workers who find themselves unable to settle in cities have the option to return home, buffers the pressure and hardships that migrants bear (Nielsen et al. 2010; Nielsen et al. 2010; Davey and Rato 2012). It is also noteworthy that conditions in the city are often perceived by migrants to be better than in rural areas (Davey and Rato 2012). Pull factors for migration, such as higher incomes and better job opportunities, may encourage migrants to hold positive attitudes towards their futures in cities.

Despite a burgeoning body of literature on subjective well-being in China, only a very small subset of it has examined the role of the Internet. A new study based on the 2010 China Family Panel Survey finds that intensive Internet penetration is negatively associated with happiness and affective well-being and that individuals' subjective perceptions of different forms of online activities have a significant effect on their self-assessments of well-being (Nie et al. 2017). Similar observations can be found in clinical researches in China, which have contributed to the previous literature by focusing on the ways in which Internet adoption shapes subjective well-being among adolescents. Accordingly, problematic and addictive Internet use is associated with increased depression and decreased life satisfaction among Chinese adolescents (Lam and Peng 2010; Wu et al. 2013). Meanwhile, other studies suggest that appropriate Internet use may improve subjective well-being (Wang and Wang 2011; Lee et al. 2008; Li et al. 2014). The central argument of these studies is that online communications can satisfy individuals' psychological needs, which consequently increases people's perceived quality of life. Despite these findings, little is known about the ways in which Internet adoption affects the subjective well-being of the millions of rural migrants in urban China. (Wei and Gao 2017) have suggested that social media use may contribute to migrants' subjective well-being. Using data collected from online surveys in popular Chinese social media sites, their analysis shows that online activities embedded in social media may help migrants to establish local social networks both on the Internet and in the real world. The information and contacts produced in social media communities on the Internet therefore tend to positively influence migrants' life satisfaction and affective balance (Wei and Gao 2017). 


\subsection{Research Questions}

The foregoing discussion suggests that the Internet has an increasingly significant impact on subjective well-being in urban China. This study, therefore, offers a comprehensive analysis of the connections between online activities and subjective well-being in urban China. Specifically, it focuses on two important issues that the previous literature has failed to address: first, existing findings have not explained how the interplay of different forms of online activities and hukou status affects subjective well-being in China. They either reflect the effect of a particular type of Internet use; e.g., (Wei and Gao 2017)—or neglect the rural-urban divide in urban China; e.g., (Lee et al. 2008).

Second, and perhaps more importantly, most previous work in this field has been based on cross-sectional data, which does not allow researchers to explore the potential impact of the dynamics of online activities on well-being across different time periods. Indeed, the ways in which changes in intensity of Internet use are associated with people's subjective well-being have rarely been explored in the Chinese context. To fill the research gaps mentioned above, this paper aims to answer the following research questions:

RQ1:How can hukou and other socioeconomic factors explain patterns of Internet adoption in urban China?

RQ2: How do patterns of the association between online activities and subjective well-being differ between rural migrants and other urban residents?

RQ3: How and in what ways does increased intensity of Internet use affect individuals' subjective well-being over time?

\section{Methods}

\subsection{Data}

The analyses in this paper are based on data from the China Family Panel Survey (CFPS), collected by the Institute of Social Science Survey at Peking University. CFPS currently consists of four waves (2010, 2012, 2014, and 2016). Covering 25 provinces, municipalities, and autonomy regions, it is one of the largest national representative panels in China. The 2010 baseline survey includes 33,600 individual respondents from 14,798 households. Because Internet use questions have only been asked in the 2010 and 2016 waves, the other two waves are not used in the empirical analysis. To distinguish between urban and rural residents, the CFPS follows the China Census Bureau's definition and identifies urban and rural subsamples in the data. The study population in this paper is restricted to the 9979 adults in the urban subsample whose information on Internet use has been collected. Finally, data collectors of the CFPS provide cross-sectional weights for selection biases, which are used in all analyses reported in this paper.

\subsection{Variables}

\subsubsection{Independent Variables}

A number of personal traits and socioeconomic controls are used in the multivariate analysis, including age, gender, marital status, hukou status, education, income, health, and social capital. Respondents' ages are coded into a categorical variable indicative of four age groups ("19 to 30", "31 to 45 ", "46 to 60 ", and "61 or above"). Marital status includes three categories, namely "married or cohabiting", "divorced or widowed", and "never married". The education variable is measured on a scale of 1 to 5 ( 1 = "illiterate or semi-literate"; 2 = "elementary"; 3 = "junior high"; $4=$ "senior high"; $5=$ "college or above"). Income is measured by logged annual household income. Respondents are asked to give a self-assessment of their own health conditions on a scale from 1 ("very bad") to 5 ("very good"). Social capital is measured by the norm of trust, which is considered as an essential ingredient of social capital (Putnam 2000). Three trust variables, indicative of trust in parents, neighbors and 
strangers, respectively, tap into the radius of trust among the respondents. Each of the three variables follows a scale of 0 to 10 , with 10 indicating the highest level of trust.

To assess the rural-urban divide in urban China, a binary variable reflecting respondents' hukou status is created. Those urban residents who have rural hukou are classified as rural migrants whereas all other respondents, including urban locals and urban-to-urban migrants, are classified as urbanites.

\subsubsection{Online Activities}

Online activities are classified into three forms according to a series questions regarding individuals' purposes when accessing the Internet. Each form consists of two types of online activities, which tend to serve distinctive purposes. The first form of online activities is called "information acquisition". Individuals who are involved in information acquisition are those who access the Internet for "study, work, and business purposes" and/or those who look for information on "professional websites" or "search engines". The second form is called "entertainment", which describes the purposes of respondents who access the Internet to "visit gaming websites" or "watching video". Lastly, respondents who are involved in "social networking" access the Internet mainly for the purpose of social interaction, including "visiting blogs" and "social media sites such as the BBS, Renren, Facebook and the like". The frequencies of these online activities are classified using a four-point Likert scale ( 1 = "never"; 2 = "less than weekly"; 3 = "weekly"; 4 = "daily").

\subsubsection{Subjective Well-Being}

Measures for subjective well-being in this study include self-reported levels of depression and life satisfaction, which reflect the affective dimension and the cognitive dimension of well-being, respectively. Depression is measured on a scale of 1 ("never feel depressed") to 5 ("feel depressed almost every day"). The CFPS also asks its respondents: "How satisfied are you with your life?" Responses to this question are coded on a five-point scale of 1 ("very unsatisfied") to 5 ("very satisfied").

Table 1 summarizes the mean scores of depression and life satisfaction in 2010 and 2016 organized according to respondents' hukou statuses. Descriptive statistics show that the overall depression level of urban residents in China increased from 2010 to 2016. Interestingly, this group of respondents became more satisfied with their lives during the same period. As compared to urbanites, rural migrants display a higher propensity to feel depressed whereas they also appear to have a higher level of life satisfaction. The differences, however, are not statistically significant $(p>0.05)$.

Table 1. Mean scores of depression and life satisfaction, by sample wave and hukou status.

\begin{tabular}{ccccc}
\hline & Depression 2010 & Depression 2016 & Life Satisfaction 2010 & Life Satisfaction 2016 \\
\hline All & 1.675 & 1.757 & 3.397 & 3.512 \\
Urbanites & 1.657 & 1.720 & 3.371 & 3.490 \\
Rural migrants & 1.698 & 1.767 & 3.412 & 3.544 \\
\hline
\end{tabular}

Source: CFPS 2010, 2016.

\subsection{Multivariate Analysis}

The multivariate analysis in this paper encompasses three parts in order to answer the three research questions. All three analyses were conducted using Stata 14. Because the measures of online activities are ordinal, ordered logistic regression estimations are adopted to examine the determinants of intensity of Internet use. Next, to examine the effects of the three forms of online activities on the two domains of subjective well-being among rural migrants and urbanites, two ordered logistic regression models were fitted with depression and life satisfaction as dependent variables.

Finally, a difference-in-differences (DID) approach is used to predict how the dynamics of different online activities affected individuals' subjective well-being from 2010 to 2016. Evolved from the propensity score matching approach, DID is particularly useful in studying the differential effect of a 
specific intervention during two or more time periods on a "treatment group" relative to a "control group" which undergoes no intervention (Card and Krueger 1994). Accordingly, urban residents in the CFPS who reported greater intensity of Internet use in 2016 as compared to 2010 are identified as the treatment group, as they constitute the group of interest on which the effects are being analyzed. Others whose frequencies of use either decreased or remained constant during the same time frame are treated as the control group. The design of the analysis can be summarized as follows: At the outset, two continuous variables were calculated as the differences between the 2016 and the 2010 self-reported depression/life satisfaction levels. Then, a regression-based DID model was developed to compare the incremental effects of increased intensity of Internet use on subjective well-being on both the treatment and control groups. The model, which is fitted with kernel matching, consists of three subsets (i.e., information acquisition, entertaining, and social networking), controlling for other independent variables, and is applied to rural migrants and urbanites, respectively. The kernel matching method is rigorous in that it matches of each of the observations in the intervened group with all observations in the control group; in addition, the propensity scores of the control group are weighted by their "distance" from a specific propensity score in the treated group. As such, the DID model is arguably an improvement over one-period models in that it allows us to examine how changes in online behavior affect subjective well-being.

\section{Results}

\subsection{Sociocultural Determinants of Internet Activities}

RQ1 asks about the effects of socioeconomic factors, especially hukou, on online activities in China. Table 2 shows ordinal regression coefficients where frequency of engagement in each form of online activity in 2010 and 2016 is the outcome variable. Results for the 2010 data are displayed in parentheses. Apart from hukou, the other control variables are age group, gender, marital status, education, income, health, and three indicators of trust. In all three models, we also control for the prior frequency of online activity (from the 2010 data).

Table 2 shows that, when other variables are controlled, urbanites appear to be significantly more active than rural migrants in all three forms of online activity. This gap is not unexpected. As a social phenomenon, the epidemic growth of the online population is much more evident in urban China as compared to rural China (World Bank 2017). Moreover, as far as economic factors are concerned, rural migrants more often lack the economic resources to purchase computers, mobile phones, or other devices that allow them to access the Internet.

Looking at other factors, we find that age is negatively associated with frequency of online activity. Single respondents tend to spend more time on the Internet than other people. Education and household income are both associated with more frequent online activity. In terms of effect size, the coefficients of education and income are more significant in the models for information acquisition (Model 1) and social networking (Model 3). While the effects of health are significant across the three models, the three trust indicators exhibit some differing effects. Moreover, trust is in general negatively associated with frequency of online activities. The effects of trusting in strangers are particularly significant in all three subsets of online activity. These results suggest that individuals who are less trusting are more likely to spend more time on the Internet. Interestingly, the results for the 2010 and the 2016 data are very similar in terms of patterns of the association between variables and the magnitudes of effects.

Table 2. Ordinal logistic regression coefficients on frequency of Internet activities.

\begin{tabular}{cccc}
\hline & Model 1 Information Acquisition & Model 2 Entertainment & Model 3 Social Networking \\
\hline Urbanites & $-0.430^{* * *}\left(0.543^{* * *}\right)$ & $-0.227^{* * *}\left(0.277^{* * *}\right)$ & $-0.240^{* * *}\left(0.199^{* * *}\right)$ \\
\hline
\end{tabular}


Table 2. Cont.

\begin{tabular}{|c|c|c|c|}
\hline & Model 1 Information Acquisition & Model 2 Entertainment & Model 3 Social Networking \\
\hline \multicolumn{4}{|c|}{ Age group (ref: 19-30) } \\
\hline $31-45$ & $-0.936^{* * *}\left(-0.940^{* * *}\right)$ & $-1.306^{* * *}\left(-1.221^{* * *}\right)$ & $-1.460^{* * *}\left(-1.344^{* * *}\right)$ \\
\hline $46-60$ & $-1.989^{* * *}\left(-1.001^{* * *}\right)$ & $-2.185^{* * *}\left(-1.920^{* * *}\right)$ & $-2.814^{* * *}\left(-1.998^{* * *}\right)$ \\
\hline 61 or above & $-2.821^{* * *}\left(-2.121^{* * *}\right)$ & $-3.302^{* * *}\left(-2.676^{* * *}\right)$ & $-3.831^{* * *}\left(-3.246^{* * *}\right)$ \\
\hline \multicolumn{4}{|l|}{ Gender (ref: male) } \\
\hline Female & $-0.042^{* * *}\left(-0.054^{* * *}\right)$ & $-0.005(-0.027)$ & $-0.035(0.044)$ \\
\hline \multicolumn{4}{|c|}{ Marriage (ref: never married) } \\
\hline Never married (ref) & & & \\
\hline Divorced or widowed & $-0.813^{* * *}\left(-0.813^{* * *}\right)$ & $-0.502^{* * *}\left(-0.516^{* * *}\right)$ & $-0.620^{* * *}\left(-0.750^{* * *}\right)$ \\
\hline Married or cohabiting & $-0.618^{* * *}\left(-0.618^{* * *}\right)$ & $-0.598^{* * *}(-0.500 * * *)$ & $-0.781^{* * *}\left(-0.731^{* * *}\right)$ \\
\hline Education & $-0.931^{* * *}\left(0.931^{* * *}\right)$ & $-0.099 *\left(0.157^{* *}\right)$ & $-0.672^{* *}(0.682 * * *)$ \\
\hline Income & $-0.003^{* * *}\left(0.003^{* * *}\right)$ & $-0.001 * *(0.003 *)$ & $-0.003^{* * *}\left(0.002^{* * *}\right)$ \\
\hline Health & $-0.246^{* * *}\left(-0.246^{* * *}\right)$ & $-0.135 * *\left(0.120^{*}\right)$ & $-0.255^{* * *}\left(0.367^{* * *}\right)$ \\
\hline Trust in parents & $-0.046^{* * *}\left(-0.046^{* * *}\right)$ & $-0.020(-0.033)$ & $-0.019(0.040)$ \\
\hline Trust in neighbors & $-0.013^{* * *}\left(-0.013^{* * *}\right)$ & $-0.071^{* *}\left(-0.107^{* * *}\right)$ & $-0.022(0.240)$ \\
\hline Trust in strangers & $-0.031^{* * *}\left(-0.031^{* * *}\right)$ & $-0.089^{* *}\left(-0.097^{* * *}\right)$ & $-0.090^{* *}\left(-0.149^{* * *}\right)$ \\
\hline Prior frequency & $-0.587^{* * *}\left(-0.587^{* * *}\right)$ & $-0.452^{* * *}\left(-0.444^{* * *}\right)$ & $-0.411^{* * *}\left(0.476^{* * *}\right)$ \\
\hline $\mathrm{N}$ & $-9957(14,491)$ & $-9957(14,491)$ & $9957(14,491)$ \\
\hline Pseudo $R^{2}$ & $-0.233(0.179)$ & $-0.284(0.198)$ & $0.323(0.276)$ \\
\hline
\end{tabular}

${ }^{*} p<0.05 ;{ }^{* *} p<0.01 ;{ }^{* * *} p<0.001$; Source: CFPS 2010, 2016. Note: Results for the 2010 data are displayed in parentheses.

\subsection{The Association between Internet Activities and Well-Being}

To compare the association between online activities and subjective well-being among urbanites and rural migrants (RQ2), two ordinal logistic regression models are fitted with self-reported levels of depression and life satisfaction as the dependent variables. As shown in Table 3, each model consists of two subsets, analyzing urbanites and rural migrants, respectively. The three forms of online activities as explanatory variables and the variables in Table 2 are simultaneously included as control variables.

First, in the model for depression, we find that rural migrants engaged with frequent online information acquisition tend to exhibit a higher level of depression, whereas its impact is weak among urbanites. Urbanites who are involved in online entertainment tend to have much lower levels of depression than their counterparts who are inactive online. By contrast, the coefficients for online entertainment show no statistical significance among rural migrants. Rural migrants reporting weekly or daily engagement in online social networking, however, exhibit a considerably lower level of depression than the reference group. Turning to the results for life satisfaction, we find that online entertainment is associated with higher life satisfaction for both urbanites and rural migrants. While online social networking is positively related to life satisfaction level among rural migrants, its impact is relatively weak among urbanites.

Overall, the three forms of online activities have a positive effect on both cognitive and affective well-being in China. However, the key point highlighted in Table 3 is that the patterns of the effects of online activities are largely different between the two sub-groups; this is discernible particularly in the analysis of depression. 
Table 3. Ordinal logistic regression coefficients on emotional and cognitive well-being.

\begin{tabular}{|c|c|c|c|c|}
\hline & \multicolumn{2}{|c|}{ Depression } & \multicolumn{2}{|c|}{ Life Satisfaction } \\
\hline & Urbanites & Rural Migrants & Urbanites & Rural Migrants \\
\hline \multicolumn{5}{|l|}{ Online activities } \\
\hline \multicolumn{5}{|c|}{ Information acquisition (ref: never) } \\
\hline Less than weekly & -0.006 & -0.105 & 0.015 & 0.096 \\
\hline Weekly & 0.153 & $-0.274 *$ & -0.027 & 0.178 \\
\hline Daily & 0.150 & $-0.248^{*}$ & -0.082 & -0.029 \\
\hline \multicolumn{5}{|l|}{ Entertainment (ref: never) } \\
\hline Less than weekly & $-0.245^{*}$ & -0.090 & -0.012 & 0.011 \\
\hline Weekly & $-0.308^{* *}$ & -0.161 & $0.241 *$ & $0.256^{*}$ \\
\hline Daily & $-0.295^{* *}$ & -0.055 & 0.290 * & $0.485^{* *}$ \\
\hline \multicolumn{5}{|l|}{$\begin{array}{c}\text { Social networking (ref: } \\
\text { never) }\end{array}$} \\
\hline Less than weekly & -0.120 & -0.106 & 0.076 & 0.104 \\
\hline Weekly & -0.037 & $-0.226^{*}$ & 0.067 & $0.171 *$ \\
\hline Daily & -0.106 & $-0.218^{*}$ & 0.041 & $0.300 * *$ \\
\hline \multicolumn{5}{|l|}{$\begin{array}{l}\text { Independent variables } \\
\text { Age group (ref: 19-30) }\end{array}$} \\
\hline $31-45$ & -0.036 & -0.004 & -0.086 & -0.016 \\
\hline $46-60$ & $-0.559 * * *$ & -0.046 & 0.130 & -0.010 \\
\hline 61 or above & $-0.721^{* * *}$ & -0.158 & $0.225^{* * *}$ & 0.018 \\
\hline \multicolumn{5}{|l|}{ Gender (ref: male) } \\
\hline Female & $-0.242 * *$ & $-0.145^{*}$ & -0.010 & -0.028 \\
\hline \multicolumn{5}{|l|}{ Marriage (ref: never married) } \\
\hline Divorced or widowed & $0.333 *$ & -0.033 & $-0.243 *$ & -0.117 \\
\hline Married or cohabiting & $0.313 *$ & -0.114 & $0.214 *$ & 0.144 * \\
\hline Education & 0.018 & $-0.092 *$ & $-0.060 *$ & 0.018 \\
\hline Income & -0.001 & $-0.006^{*}$ & $0.001^{*}$ & -0.003 \\
\hline Health & $-0.130 * * *$ & $-0.119 * * *$ & $0.181^{* * *}$ & $0.059^{* * *}$ \\
\hline Trust in parents & $-0.041 *$ & -0.023 & $0.121^{* * *}$ & $0.060 * * *$ \\
\hline Trust in neighbors & $-0.106^{* * *}$ & $-0.098^{* * *}$ & $0.148^{* * *}$ & $0.079 * * *$ \\
\hline Trust in strangers & -0.008 & -0.028 & 0.004 & -0.007 \\
\hline Prior well-being scores & $0.517^{* * *}$ & $0.327^{* * *}$ & $0.562^{* * *}$ & $0.276^{* * *}$ \\
\hline $\mathrm{N}$ & 5511 & 4435 & 5511 & 4435 \\
\hline Pseudo $R^{2}$ & 0.071 & 0.074 & 0.061 & 0.057 \\
\hline
\end{tabular}

\subsection{Results from Difference-in-Differences Models}

\subsubsection{Exploring Changes in the Intensity of Online Activity}

The attention devoted to the dynamics of online activities motivates a closer examination of how changes in online activities may affect individuals' subjective well-being (RQ3). To capture such changes, we compare individuals' frequencies of use of each of the three forms of online activities according to the 2010 and the 2016 CFPS data. Given that the variable uses a four-point Likert scale, the differences between an individual's 2010 and 2016 frequencies are classified using the following strategy: If there is no difference between the individual's 2010 and 2016 frequencies, his/her Internet use is termed 'unchanged'; if there is a difference of one point, he/she is considered to have had 'similar' frequencies of use in 2016 and 2010; if the frequency increased by two or three points in 2016, the individual is classified as showing increased engagement in Internet use; if the frequency decreased by two or three points in 2016, the individual is classified as showing decreased engagement in Internet use. The abovementioned classifications are illustrated in Table 4. 
Table 4. Changes in frequency of online activities between 2010 and 2016.

\begin{tabular}{|c|c|c|c|c|}
\hline & \multicolumn{4}{|c|}{2016 Frequencies } \\
\hline & Never & Less than Weekly & Weekly & Daily \\
\hline \multicolumn{5}{|l|}{2010 Frequencies } \\
\hline Never & Unchanged & Similar & Increased & Increased \\
\hline Less than weekly & Similar & Unchanged & Similar & Increased \\
\hline Weekly & Decreased & Similar & Unchanged & Similar \\
\hline Daily & Decreased & Decreased & Similar & Unchanged \\
\hline
\end{tabular}

Table 5 shows changes in participants' frequencies of online activities between 2010 and 2016. The descriptive results indicate an overall increased frequency of online activities from 2010 to 2016. In all three forms of online activities, observably larger numbers of respondents became more active than less active. The highest rates of increased engagement in online activities can be found in online social networking: $18.3 \%$ of urbanites and $15.6 \%$ of rural migrants were involved in online social networking more frequently in 2016 than in 2010. Of the three types of online engagement, information acquisition has the lowest rates of increased engagement as well as the highest rates of decreased engagement. Moreover, the rates of increased engagement were higher among urbanites than rural migrants. Overall, however, the results exhibited in Table 5 reveal a more vibrant online society in urban China. The Internet has clearly been playing an increasingly important role in the lives of both urbanites and rural migrants.

Table 5. Changes in frequency of online activities, between 2010 and 2016.

\begin{tabular}{cccccc}
\hline & Downward & Upward & Other & Downward \% & Upward \% \\
\hline Information acquisition & & & & & \\
$\quad$ Urbanites & 289 & 697 & 4725 & $5.1 \%$ & $12.2 \%$ \\
Rural migrants & 156 & 340 & 4468 & $3.1 \%$ & $7.0 \%$ \\
\hline Entertainment & & & & \\
$\quad$ Urbanites & 216 & 865 & 4630 & $3.8 \%$ & $15.7 \%$ \\
Rural migrants & 60 & 524 & 4380 & $1.2 \%$ & $13.5 \%$ \\
\hline Social networking & & & & & \\
$\quad$ Urbanites & 56 & 1069 & 4586 & $1.0 \%$ & $18.3 \%$ \\
Rural migrants & 15 & 628 & 4321 & $0.3 \%$ & $15.6 \%$ \\
\hline
\end{tabular}

Source: CFPS 2010, 2016.

\subsubsection{How Spending More Time on the Internet Affects Subjective Well-Being}

Finally, a difference-in-differences approach was employed to estimate the effect of increased frequency of different forms of online activities on individuals' subjective well-being over time. In each subset, Group B consisted of respondents who reported increased engagement in a specific online activity from 2010 to 2016, while Group A included all other respondents (see also results in Table 5). The main purpose for this categorization is to differentiate respondents with more active online engagement, which allows us to explore the impact of different forms of online activities over time. The model assumed the dataset mid-point as the intervention date. Using kernel matching, the regression-based DID model reports how much the differences in subjective well-being between Groups A and B have been shaped by the dynamics of online activities. To address potential sources of bias, we included five covariates in the multivariate analysis, namely age, gender, education, income, and health. The tests of the balancing property of the propensity scores indicate satisfying results in the analyses for both urbanites and rural migrants. The model results are summarized in Tables 6 and 7. Each table first reports the mean scores of depression and life satisfaction of the two groups and then displays the results from the DID model. The study population of the analysis is 5418 . 
Looking first at the results for urbanites in Table 6, we find in the descriptive statistics that there is an increase in levels of both depression and life satisfaction in groups A and B. In the subset for online entertainment, the increase in individuals' depression level is much lower in the Group B than in Group A $(-0.099, p=0.002)$, while results for life satisfaction $(0.091, p=0.011)$ move in the opposite direction. The remarkable margins in the differences between the two groups in 2010 and 2016 suggest that increased intensity in online entertainment is associated with great subjective well-being in both cognitive and affective terms. It is worth mentioning that increased engagement in online information acquisition tends to have more of a negative impact on depression and life satisfaction among members of Group B, although this impact is not statistically significant.

Table 6. Comparison of mean scores of depression and life satisfaction and adjusted differencein-difference estimates of the impact of online activities on subjective well-being among urbanites, 2010-2016.

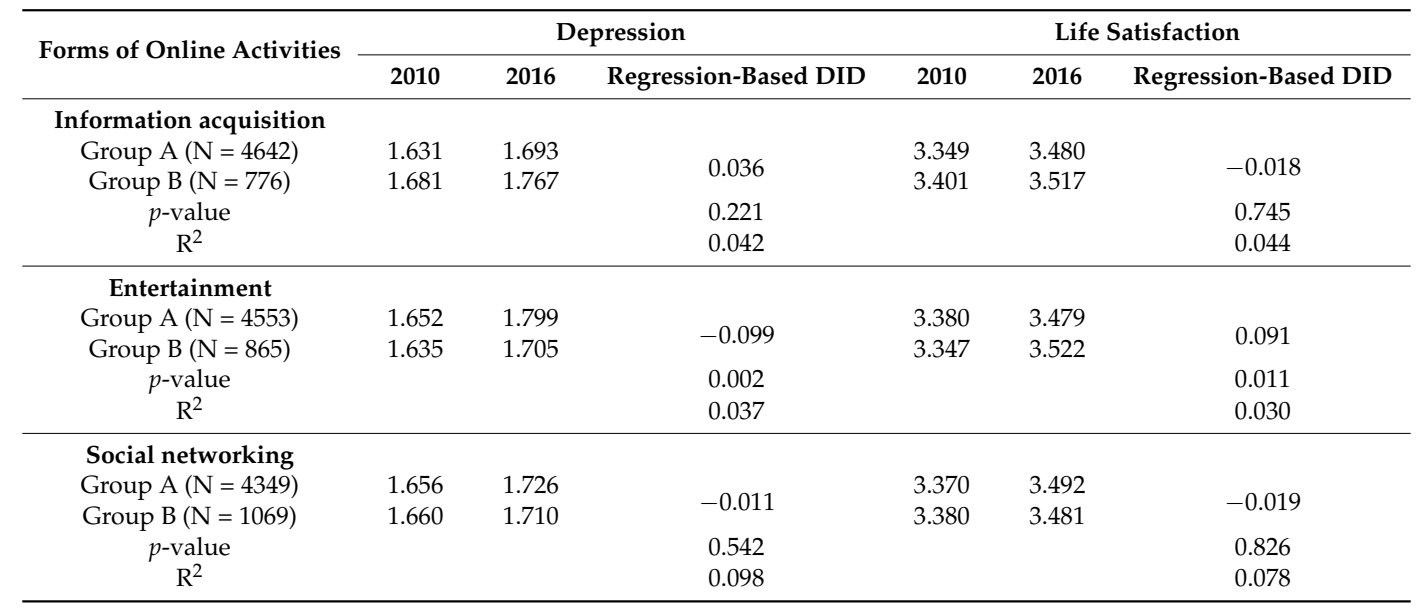

Source: CFPS 2010, 2016.

Table 7 shows the results for rural migrants. Similar to the results displayed in Table 6, the mean scores for depression and life satisfaction also slightly increased in the 2016 CFPS data. The first point to note in Table 7 is that increased engagement in online social networking presents significant effects in the analysis: in contrast to Group A, the increase in depression is much lower $(-0.086, p=0.008)$ in Group B, whereas the increase in life satisfaction is discernibly higher in Group B $(0.052, p=0.036)$. This suggests that increased frequency of online social networking has a more positive impact on the subjective well-being of rural migrants than it does on urbanites in the Chinese city. Furthermore, intensified online entertainment is found to contribute to an increased gap in subjective well-being between Group A and Group B, although the magnitude of the effect is greater in the case of life satisfaction $(0.077, p=0.027)$ than depression $(-0.067, p=0.078)$. In addition, the increase in depression in Group B appears to exceed that of Group A in the models for information acquisition, suggesting that online information acquisition has a negative impact on subjective well-being over time. 
Table 7. Comparison of mean scores of depression and life satisfaction and adjusted differencein-difference estimates of the impact of online activities on subjective well-being among rural migrants, 2010-2016.

\begin{tabular}{|c|c|c|c|c|c|c|}
\hline \multirow{2}{*}{ Forms of Online Activities } & \multicolumn{3}{|c|}{ Depression } & \multicolumn{3}{|c|}{ Life Satisfaction } \\
\hline & 2010 & 2016 & Regression-Based DID & 2010 & 2016 & Regression-Based DID \\
\hline \multicolumn{7}{|l|}{ Information acquisition } \\
\hline Group A $(\mathrm{N}=4092)$ & 1.689 & 1.754 & \multirow{2}{*}{-0.002} & 3.411 & 3.546 & \multirow{2}{*}{-0.035} \\
\hline Group B $(\mathrm{N}=469)$ & 1.705 & 1.773 & & 3.412 & 3.538 & \\
\hline$p$-value & & & \multirow{2}{*}{$\begin{array}{l}0.881 \\
0.043\end{array}$} & & & \multirow{2}{*}{$\begin{array}{l}0.211 \\
0.039\end{array}$} \\
\hline $\mathrm{R}^{2}$ & & & & & & \\
\hline \multicolumn{7}{|l|}{ Entertainment } \\
\hline Group A $(\mathrm{N}=4037)$ & 1.706 & 1.806 & \multirow{2}{*}{-0.067} & 3.420 & 3.532 & \multirow{2}{*}{0.077} \\
\hline Group B $(\mathrm{N}=524)$ & 1.696 & 1.745 & & 3.398 & 3.590 & \\
\hline$p$-value & & & \multirow{2}{*}{$\begin{array}{l}0.078 \\
0.027\end{array}$} & & & \multirow{2}{*}{$\begin{array}{l}0.027 \\
0.031\end{array}$} \\
\hline$R^{2}$ & & & & & & \\
\hline \multicolumn{7}{|l|}{ Social networking } \\
\hline Group A $(\mathrm{N}=3933)$ & 1.651 & 1.808 & \multirow[b]{2}{*}{-0.086} & 3.407 & 3.524 & \multirow{2}{*}{0.052} \\
\hline Group B $(\mathrm{N}=628)$ & 1.687 & 1.730 & & 3.419 & 3.599 & \\
\hline$p$-value & & & \multirow{2}{*}{$\begin{array}{l}0.008 \\
0.065\end{array}$} & & & \multirow{2}{*}{$\begin{array}{l}0.036 \\
0.051\end{array}$} \\
\hline$R^{2}$ & & & & & & \\
\hline
\end{tabular}

Source: CFPS 2010, 2016.

\section{Discussion}

This study investigates the socioeconomic characteristics of Internet adoption and the association between different forms of online activities and subjective well-being among urban Chinese dwellers. Specifically, a difference-in-differences model was fitted with data from the Chinese Family Panel Studies to examine how the burgeoning online society in urban China affects depression and life satisfaction among urbanites and rural migrants. As far as we know, this is the first study to use panel data to examine trends in the impact of Internet adoption on both urbanites and rural migrants over time.

Our findings show that the patterns of the online activities considered tend to reflect differences in personal traits and social standing. There is a clear rural-urban distinction in terms of the degree of Internet penetration among urban residents in China, with urban hukou holders shown to be more regularly engaged in online activities than rural hukou holders. Overall, users of online information acquisition, entertainment, and social networking appear to have similar socioeconomic characteristics. As we expected, younger people and single respondents are more active users of the Internet. Education, income, and health are also positively associated with frequency of online activities. Another salient finding is that trust levels, especially trust in strangers, have negative effects on respondents' online behaviors. This finding coincides with some existing studies that suggest a negative correlation between Internet penetration and real-life relationships (Nie et al. 2017; Putnam 2000). We thus speculate that distrust and lack of social capital may serve as mechanisms that motivate individuals to spend more time on the Internet; doing so, in turn, further reduces individuals' real-life social networks.

Results in the ordinal logistic regression model based on cross-sectional data reveal an overall positive association between frequency of Internet usage and subjective well-being in urban China, which echoes findings in the previous literature (Wang and Wang 2011; Lee et al. 2008; Li et al. 2014). However, the key point is that the patterns of such associations appear to differ between urbanites and rural migrants. For example, while some recent findings suggest that online social networking is positively related to subjective well-being among Chinese citizens (Oh et al. 2014; Stepanikova and He 2010; Nie et al. 2017); our finding indicates that this effect is considerably greater among rural migrants than urbanites. We find similar patterns in our analysis for depression: online entertainment is associated with lower levels of depression among urbanites but displays limited effects among rural migrants; the effects of online information acquisition, however, take the opposite form. These findings, mirroring the imprints of the hukou system, make it feasible to distinguish the divergent effects of Internet adoption in urban China. They suggest that the relationship between online activities and 
subjective well-being is subject to the unique social structure of urban China, which has segmented residents into two distinctive groups.

The descriptive results in the analysis do reveal that a more vibrant Internet community has emerged in urban China. From 2010 to 2016, both rural migrants and urbanites have become more engaged in all three forms of online activities under consideration, as rates of intensified online activities have clearly exceeded rates of decreased engagement. Consequently, a difference-in-differences regression model was used to assess how the dynamics of online activities affect cognitive and affective well-being in urban China.

The results of the DID model reveal that different forms of online activities have distinct effects on individuals' subjective well-being over time. In contrast to findings derived from cross-sectional data, our results show that increased engagement in online information acquisition appears to have a negative impact on residents' subjective well-being in urban China, although the magnitude of this impact is relatively small. As the nature of the DID model compares relative differentials between two time periods rather than difference at one particular point (Card and Krueger 1994), it shows that the longitudinal effect of online engagement tend to differ from that of its 'still' form. In other words, while there is a moderate association between online information acquisition and subjective well-being, continuous engagement in this particular online activity tends to be indicative of a more negative change in individuals' subjective well-being overtime. Indeed, the similar patterns between results for the 2010 and 2016 data in the ordinal logit regression suggest that the effect of time matters. While results from some longitudinal studies in Western societies indicate that seeking information is positively related to well-being (Freese et al. 2006; Lissitsa and Chachashvili-Bolotin 2016), our study shows a different pattern in the context of urban China. On the contrary, the effects of intensified online engagement in the other two forms of online activities are more positive. Increased use of online entertainment is shown to improve results in the subjective well-being of both urbanites and rural migrants. Previous studies have found that online entertainment may foster positive feelings and satisfy users' psychological needs (Ryan et al. 2006; Li et al. 2014). It is thus plausible that it plays a similar role in the context of urban China, where people, particularly migrants, often face various sorts of pressure (Wu and Treiman 2004; Treiman 2012). Similarly, increased usage of online social networking is found to have a strongly positive impact on rural migrants' subjective well-being, whereas it has only a limited impact on urbanites.

Another important finding concerns identity-related differences in the results for online entertainment and social networking. We find that increased engagement with online entertainment has a more positive impact on depression among urbanites than among rural migrants. A more notable difference can be discerned in the model showing the association between increased usage of online social networking and greater subjective well-being among rural migrants. However, this pattern is not found among urbanites. Many have argued that rural migrants in Chinese cities often lack local social networks and social support (Wu and Treiman 2004; Wu et al. 2013). In this context, the online community tends to serve as an incubator that fosters and maintains social interactions for rural migrants in their host cities. Moreover, as online social interactions are likely to lower the physical and mental costs of social involvement, they may enhance rural migrants' sense of belonging and satisfy their psychological needs (Nie et al. 2017; Wei and Gao 2017). The distinction between urbanites and rural migrants provides new findings about the ways in which the imprints of the hukou system shape patterns of online activities and about the impact of those activities on subjective well-being in urban China.

\section{Conclusions}

This study yields a number of important findings. In urban China, hukou identity and socioeconomic position appear to be strongly associated with individuals' online behavior. Although rural migrants are less active Internet uses than urbanites, both groups tended to spend more time online in 2016 than in 2010. Results from our cross-sectional analysis show that the frequencies of online 
information acquisition, entertainment, and social networking are in general positively associated with cognitive and affective well-being, though the patterns of such associations differ among rural migrants and urbanites. Using a difference-in-differences approach, our analysis shows that increased engagement in online entertainment exhibits a significantly positive effect on subjective well-being. Spending more time on online social networking tends to improve rural migrants' subjective well-being, while it displays no significant effect on urbanites. There is a negative and modest association between increased engagement in online information acquisition and subjective well-being in Chinese cities.

The current study has several implications. Methodologically, the difference-in-differences approach aids in the interpretation of previous findings based on cross-sectional data, which are unable to establish any causal relationships among variables. There is currently a paucity of research using panel data in this terrain. Therefore, future studies may advance the understanding of the association between well-being and Internet adoption by taking advantage of the growing body of longitudinal social surveys such as CFPS in China. Empirically, the analyses in this paper demonstrate an observable connection between the dynamics of urban Chinese residents' online activities and those individuals' subjective well-being over time. While scholars have been calling for closer examination of determinants of subjective well-being in China (Davey and Rato 2012; Easterlin et al. 2012; Jiang et al. 2012), we would argue that the Internet is becoming increasingly significant in shaping the subjective well-being of Chinese people. It is thus important for academics and policy makers to understand the long-term effects of urban China's unpreceded digital movement and the varied influences that the outcomes are having on residents' subjective well-being. Meanwhile, our study provides strong evidence for the presence of identity-related disparities in online behaviors and subjective well-being in urban China. For a society with the inherent social segmentation that is embedded in the hukou system, the Internet community may serve as a lubricant for the social integration of rural migrants, who are most sensitive to hukou-related inequalities and segregation.

\section{Limitations}

We are aware that the present study has several limitations. First, notwithstanding its implications discussed above, the results of the DID model should be interpreted conservatively. The main limitation concerns the use of self-reported frequency of online activities, as the treatment variable may affect our conclusions. Such frequency might have changed more than once between the two waves, although we have attempted to reduce this possibility by restricting Group B to those who moved more than two points on the relevant Likert scale. Another limitation arises from the fact that our analyses did not account for certain important factors. In particular, the previous literature has pointed to the significant generational and regional differences in well-being among urban Chinese residents (Cheng et al. 2013; Bian and Xiao 2014). However, we were unable to control these variables due to a limited sample size.

Author Contributions: The authorship of this article belongs fully to Y.H.

Funding: This research is supported by Hallsworth China Political Economy Fund.

Conflicts of Interest: The author declares no conflict of interest.

\section{References}

Anderson, Ronald. 2014. Human Suffering and Quality of Life: Conceptualizing Stories and Statistics. New York: Springer.

Bian, Yanjie, and Yang Xiao. 2014. A comparative analysis of subjective well-being in China and Britain (in Chinese). Sociological Studies 29: 22-42.

Blanchflower, Davod, and Andrew Oswald. 2008. Is well-being U-shaped over the life cycle? Social Science and Medicine 66: 1733-49. [CrossRef] [PubMed]

Blore, Jed, Mark Stokes, David Mellor, Lucy Firth, and Robert Cummins. 2011. Comparing multiple discrepancies theory to affective models of subjective well-being. Social Indicators Research 100: 1-16. [CrossRef] 
Bonini, Astra. 2008. Cross-national variation in individual life satisfaction: Effects of national wealth, human development, and environment conditions. Social Indicators Research 87: 223-36. [CrossRef]

Caplan, Scott. 2002. Problematic internet use and psychosocial well-being: Development of a theory-based cognitive behavioral measurement instrument. Computers in Human Behavior 18: 553-75. [CrossRef]

Card, David, and Alan Krueger. 1994. Minimum wages and employment: A case study of the fast-food industry in New Jersey and Pennsylvania. The American Economic Review 84: 772-93.

Cheng, Cecilia, and Angel Li. 2014. Internet addiction prevalence and quality of (real) life: A meta-analysis of 31 nations across seven world regions. Cyberpsychology, Behavior, and Social Networking 17: 755-60. [CrossRef] [PubMed]

Cheng, Zhiming, Haining Wang, and Russel Smyth. 2013. Happiness and job satisfaction in urban China: A comparative study of two generations of migrants and urban locals. Urban Studies 51: 2160-84. [CrossRef]

Cummins, Robert. 1995. On the trail of the gold standard for life satisfaction. Social Indicators Research 35: 179-200. [CrossRef]

Curran, James, Sharon Coen, Torila Aalberg, Kaori Hayashi, Papathanassopoulo Jones, Sergio Splendore, Stylianos Papathanassopoulos, David Rowe, and Rodney Tiffen. 2013. Internet revolution revisited: A comparative study of online news. Media, Culture E Society 35: 880-97.

Davey, Gareth, and Ricardo Rato. 2012. Subjective wellbeing in China: A review. Journal of Happiness Studies 13: 333-46. [CrossRef]

Diener, Ed. 2000. Subjective well-being: The science of happiness and a proposal for a national index. American Psychologist 55: 34-43. [CrossRef] [PubMed]

Diener, Ed, and Carol Diener. 1995. The wealth of nations revisited: Income and quality of life. Social Indicators Research 36: 275-86. [CrossRef]

DiMaggio, Paul, Eszter Hargittai, Carol Celeste, and Steven Shafer. 2004. Digital inequality: From unequal access to differentiated use. In Social Inequality. Edited by Kathryn Neckerman. New York: Russell Sage Foundation, pp. 355-400.

Dolan, Pail, Tessa Peasgood, and Mathew White. 2008. Do we really know what makes us happy? A review of the economic literature on the factors associated with subjective well-being. Journal of Economic Psychology 29: 94-122. [CrossRef]

Easterlin, Richard. 1974. Does economic growth improve the human lot? Some empirical evidence. In Nations and Households in Economic Growth: Essays in Honor of Moses Abramovitz. Edited by David Paul and Warren Melvin. New York: Academic Press, Inc.

Easterlin, Richard. 2003. Explaining happiness. Proceedings of the National Academy of the Sciences of the United States of America 100: 11176-83. [CrossRef] [PubMed]

Easterlin, Richard, Robson Morgan, Malgorzata Switek, and Fei Wang. 2012. China's life satisfaction, 1990-2010. Proceedings of the National Academy of the Sciences of the United States of America 109: 9775-80. [CrossRef] [PubMed]

Elgar, Frank, Christopher Davis, Michael Wohl, Stephen Trites, John Zelenski, and Michael Martin. 2011. Social capital, health and life satisfaction in 50 countries. Health and Place 17: 1044-53. [CrossRef] [PubMed]

Fowler, Jie, James Gentry, and Timothy Reisenwitz. 2015. Analyzing Chinese older people's quality of life through their use of the internet. International Journal of Consumer Studies 39: 324-34. [CrossRef]

Freese, Jeremy, Salvador Rivas, and Eden Hargittai. 2006. Cognitive ability and internet use among older adults. Poetics 34: 236-49. [CrossRef]

Greenberg, Alva, Gullotta Thomas, and Martin Bloom. 2016. Social Capital and Community Well-Being: The Serve Here Initiative. New York: Springer.

Helliwell, John. 2006. Well-being, social capital and public policy: What's new? The Economic Journal 116: 34-45. [CrossRef]

Hicks, Stephen. 2011. Spotlight on: Subjective Wellbeing. Office for National Statistics. Available online: http:/ / www.ons.gov.uk/ons/rel/social-trends-rd/social-trends/spotlight-on-subjective-well-being/artspotlight-on-subjective-well-being.pdf?format=hi-vis / (accessed on 12 August 2017).

Jiang, Shiming, Ming Lu, and Hiroshi Sato. 2012. Identity, inequality, and happiness: Evidence from urban China. World Development 40: 1190-200. [CrossRef]

Knight, John, and Ramani Gunatilaka. 2010. Great expectations? The subjective wellbeing of rural-urban migrants in China. World Development 38: 113-24. [CrossRef] 
Lam, Laurence, and Zi-Wen Peng. 2010. Effect of pathological use of the Internet on adolescent mental health: A prospective study. Archives of Pediatrics and Adolescent Medicine 164: 901-6. [CrossRef] [PubMed]

Lee, Paul, Louis Leung, Venhwei Lo, and Chengyu Xiong. 2008. The perceived role of ICTs in quality of life in three Chinese cities. Social Indicators Research 88: 457-76. [CrossRef]

Li, Caina, Xinxin Shi, and Jianming Dang. 2014. Online communication and subjective well-being in Chinese college students: The mediating role of shyness and social self-efficacy. Computers in Human Behavior 34: 89-95. [CrossRef]

Li, Yaojun, Shun Zhang, and Jianxun Kong. 2015. Social mobility in China and Britain: A comparative study. International Review of Social Research 5: 20-34. [CrossRef]

Lim, Chaeyoon, and Robert Putnam. 2010. Religion, social networks, and life satisfaction. American Sociological Review 75: 914-33. [CrossRef]

Lissitsa, Sabina, and Svetlana Chachashvili-Bolotin. 2016. Life satisfaction in the internet age-Changes in the past decade. Computers in Human Behavior 54: 197-206. [CrossRef]

McKenna, Katelyn, and John Bargh. 2000. Plan 9 from cyberspace: The implications of the Internet for personality and social psychology. Personality and Social Psychology Review 4: 57-75. [CrossRef]

Nie, Peng, Alfonso Sousa-Poza, and Galit Nimrod. 2017. Internet use and subjective well-being in China. Social Indicators Research 132: 489-516. [CrossRef]

Nielsen, Igrid, Olga Paritski, and Russel Smyth. 2010. Subjective wellbeing of Beijing taxi drivers. Journal of Happiness Studies 11: 721-33. [CrossRef]

Nielsen, Ingrid, Russel Smyth, and Qingguo Zhai. 2010. Subjective wellbeing of China's off-farm migrants. Journal of Happiness Studies 11: 315-33. [CrossRef]

O'Keeffe, Gwenn, and Kathleen Clarke-Pearson. 2011. The impact of social media on children, adolescents, and families. Pediatrics 127: 800-4.

Oh, Hyun-Jung, Elif Ozkaya, and Robert LaRose. 2014. How does online social networking enhance life satisfaction? The relationships among online supportive interaction, affect, perceived social support, sense of community, and life satisfaction. Computers in Human Behavior 30: 69-78. [CrossRef]

Putnam, Robert. 2000. Bowling Alone: The Collapse and Revival of American Community. New York: Simon and Schuster.

Rao, Manoj Kumar, Preeti Tamta, and Pratima Kumari. 2014. The impact of age, education and residential setting (community) on health status and life satisfaction. Indian Journal of Health and Wellbeing 5: 485-88.

Ryan, Ricard, Scott Rigby, and Amdrew Przybylski. 2006. The motivational pull of video games: A selfdetermination theory approach. Motivation and Emotion 30: 344-60. [CrossRef]

Stepanikova, Irema. Norman Nie, and Xiaobin He. 2010. Time on the internet at home, loneliness, and life satisfaction: Evidence from panel time-diary data. Computers in Human Behavior 26: 329-38. [CrossRef]

Stiglitz, Josepn, Amartya Sen, and Jean-Paul Fitoussi. 2009. The Measurement of Economic Performance and Social Progress. Paris: Centre de recherche en économie de Sciences Po, No. 2009-33.

Treiman, David. 2012. The 'difference between heaven and earth': Urban-rural disparities in well-being in China. Research in Social Stratification and Mobility 30: 33-47. [CrossRef]

Valkenburg, Path, and Jochen Peter. 2007. Online communication and adolescent wellbeing: Testing the stimulation versus the displacement hypothesis. Journal of Computer-Mediated Communication 12: 1169-82. [CrossRef]

Visser, Mandy, Marjolijn Antheunis, and Alexander Schouten. 2013. Online communication and social well-being: How playing World of Warcraft affects players' social competence and loneliness. Journal of Applied Social Psychology 43: 1508-17. [CrossRef]

Wang, Jinliang, and Haizhen Wang. 2011. The predictive effects of online communication on well-being in among Chinese adolescents. Psychology 2: 359-62. [CrossRef]

Wei, Lu, and Fangfang Gao. 2017. Social media, social integration and subjective well-being among new urban migrants in China. Telematics and Informatics 34: 786-96. [CrossRef]

Wong, Daviel, Yingli Chang, and Xuesong He. 2007. Rural migrant workers in urban China: Living a marginalised life. International Journal Social Welfare 16: 32-40.

World Bank. 2017. Individuals Using the Internet (\% of Population). Available online: https:/ / data.worldbank. org/indicator/IT.NET.USER.ZS/ (accessed on 13 August 2017). 
Wu, Xiaogang, and Donald Treiman. 2004. The household registration system and social stratification in China: 1955-1996. Demography 41: 363-84. [CrossRef] [PubMed]

Wu, Xianhua, Xinguang Chen, Juan Han, Heng Meng, Jianghong Luo, Liesl Nydegger, and Hanrong Wu. 2013. Prevalence and factors of addictive Internet use among adolescents in Wuhan, China: Interactions of parental relationship with age and hyperactivity-impulsivity. PLoS ONE 8: e61782. [CrossRef] [PubMed]

Yip, Winnie, S. V. Subramanian, Amdrew Mitchell, Dominic Lee, Jian Wang, and Ichiro Kawachi. 2007. Does social capital enhance health and well-being? Evidence from rural China. Social Science and Medicine 64: 35-49. [CrossRef] [PubMed]

(C) 2018 by the author. Licensee MDPI, Basel, Switzerland. This article is an open access article distributed under the terms and conditions of the Creative Commons Attribution (CC BY) license (http:/ / creativecommons.org/licenses/by/4.0/). 